\title{
PARASITISM IN YOUNG ANIMALS
}

\author{
G. M. URQUHART
}

SUMMARY

Pulmonary and gastrointestinal helminthiasis in young ruminants is usually followed by the development of immunity and lifelong freedom from disease. However, the recent advent of very effective systems of anthelmintic prophylaxis during the first year of life poses questions about the degree of immunity which animals might be expected to possess in later life. Aspects of this are discussed and, since bovine dictyocauliasis is potentially the most serious, the possibility of immunisation of older cattle, rather than calves, is suggested.
RÉSumé : Parasitisme chez les jeunes animaux.

Le développement, chez les jeunes ruminants, d'un état d'immunité, caractérisé par l'absence de maladie chez les animaux plus âgés, succède généralement aux helminthoses digestives et pulmonaires. Cependant, les nouveaux systèmes très efficaces de prophylaxie des helminthoses, mis en place chez les ruminants de pre- mière année de pâture, remettent en question le degré de protection qu'ont pu acquérir ces animaux. Ces aspects sont discutés et, puisque la dictyocaulose est potentiellement la plus menaçante des helminthoses bovines, la possibilité est suggérée d'immuniser les bovins âgés, plutôt que les veaux.
It is very dangerous to make a categoric statement about parasitism but since I have to start somewhere I would like to suggest that in endemic situations clinical signs of parasitic disease are usually confined to young animals.

This seems to be due to one of two reasons. The first, and less common, is that some parasites are only able to infect their hosts when the latter are very young; older animals, even with no previous experience of infection, are highly refractory to infection. Examples of this situation are Toxocara canis infection in the dog and Strongyloides and Cryptosporidium infection in ruminants. The basis of this age resistance is obscure although it has been suggested that it is an indication that the host-parasite relationship is relatively new and still ill-adapted in an evolutionary sense.

The second and more common reason is that the young host, having experienced and survived a parasitic infection, develops an acquired immunity; this, although it may not completely prevent reinfection, reduces it to the extent that the host is clinically unaffected and becomes, in effect, a symptomless carrier. In veterinary parasitology the most common examples are the nematodes species causing parasitic bronchitis and parasitic gastroenteritis in ruminants. Although we are still attempting to understand the basis of this immunity it is no exaggeration to say that the health of our flocks and herds, especially in the intensive systems practised today, depend on the daily ability of these immune

Faculty of Veterinary Medicine, The University of Glasgow, Bearsden road, Glasgow G61 19H, Scotland. animals to destroy otherwise lethal intakes of nematode larvae.

It is at this point that $\mathrm{I}$ wish to stop generalising and instead to discuss some recent systems introduced for the control of pulmonary and gastrointestinal nematode diseases of young animals and to speculate on their possible effect on the acquisition of immunity in older animals. Since these systems are most advanced in cattle I will confine myself to this species.

For years the prevention of parasitic gastroenteritis and parasitic bronchitis in calves has largely rested on the application of certain well-established principles.

For parasitic gastroenteritis, several methods are commonly practised, the most popular being the « dose and move » technique in which grazing calves are treated with an anthelmintic in mid-July and immediately moved to " clean " pasture such as silage or hay aftermath.

Because of the ubiquity and persistence of lungworm larvae on pasture and the small number which, if ingested, will produce clinical disease none of these traditional methods can be relied on to prevent parasitic bronchitis and the control of this disease in endemic areas largely depends on an annual programme of calf vaccination.

An assumption, common to all these approaches, is that the prevention of these two diseases is a problem involving calves during their first grazing season only. In practice this is almost always the case since all of these systems invariably expose calves to a certain degree of challenge with infective larvae so that by the end of their first year they have developed a high degree of immunity. This immu- 
nity is reinforced in subsequent years by re-exposure to infection so that clinical signs are absent and further treatment is unnecessary.

More recently, however, two new systems have been introduced for the control of lung and gastrointestinal nematodes. First, the oxfendazole pulse release bolus (OPRB) which, given at turnout, liberates a therapeutic dose of the drug every three weeks (i. e. the approximate prepatent period of the nematodes) on five separate occasions. Thus, for a period of four months the calves harbour very few adult worms and in practice trichostrongyle egg output is reduced by around $98 \%$ during the grazing season while lungworm infection is also suppressed (Jacobs et al., $1987 a, b, c)$.

The second is the use of ivermectin at intervals of 3 , 8 and 13 weeks after the calves have gone to grass. Because of small residues of the drug in the plasma of the host there is a prophylactic interval after each dose of at least 7 and 14 days during which infection with gastrointestinal and lungworm larvae respectively is largely prevented. Since the drug is administered at intervals of five weeks this means that very few stomach or intestinal worms develop to patency for a period of four months. The development of lungworms, which are particularly sensitive to the drug, is even more efficiently suppressed and faecal larval output may be completely negative over this period (Armour et al., 1987).

There is little doubt that both of these new approaches are generally successful in preventing clinical signs of pulmonary and gastrointestinal parasitism during the first grazing season. However, it is important to establish whether calves develop as high a degree of immunity to reinfection as with the established systems so that further treatment in later years is unnecessary.

The results so far available indicate that calves treated with either system of anthelmintic suppression and exposed to a significant degree of challenge will develop an adequate immunity to both lungworms and gastrointestinal worms (Jacobs et al., 1987 c; Armour et al., 1988). Unfortunately the phrase " a significant degree of challenge " cannot ever be guaranteed and if lungworm challenge, in particular, is absent or trivial in any particular year the stock will acquire little or no immunity. This situation may well become exacerbated by the use of either of these systems over several years when the larval populations on pasture may become so reduced that yearlings or older cattle may acquire little or no immunity to pulmonary and gastrointestinal nematodes.

As far as gastrointestinal nematodes are concerned one can visualise three possible scenarios. First, one could con- sider that each year calves will ingest sufficient numbers or larvae, especially in the later part of the grazing season, to stimulate an adequate degree of immunity and that the adult worm burdens acquired will ensure contamination of the pastures with infective larvae so that immunity will be reinforced in subsequent years. Secondly, if this does not happen, one might argue that the virtual disappearance of gastrointestinal nematode infections on pasture can only be a matter of congratulation. While this parasitefree status might operate successfully in a closed herd it is likely that in other situations the third scenario, namely, a continuation of anthelmintic therapy in older cattle might be necessary.

With parasitic bronchitis, the situation is less clear because of the unpredictable epidemiology of the disease, possibly associated with extended larval survival and dispersion of larvae by the fungus Pilobolus. This annual unpredictability is undoubtedly the reason why severe and sometimes explosive outbreaks of parasitic bronchitis in adult cattle are not infrequently encountered due presumably to a lack of immunity and a massive larval challenge. If one believes that it is desirable to maintain a herd immunity to lungworm infection in these circumstances it seems to me that a possible route of the dilemma is the option of adult vaccination as suggested by Taylor (1988).

Meantime, until more information is available, veterinarians should be aware of the possibility that parasitic bronchitis and gastroenteritis may be encountered more frequently in older cattle due to insufficient larval challenge as young animals and a subsequent lack of immunity.

\section{REFERENCES}

Armour J. et al. : Control of parasitic bronchitis and gastroenteritis in grazing cattle by strategic prophylaxis with ivermectin. Vet. Rec., 1987, 121, 5-8.

Armour J. et al. : Immunity of ivermectin treated cattle to challenge from helminth parasites in the following season. Vet. Rec., 1988, 122, 223-225.

Jacobs D. E. et al. : Field evaluation of the oxfendazole pulse release bolus for the chemoprophylaxis of bovine parasitic gastroenteritis. J. Vet. Pharmacol. Ther., 1987 a, 10, 30-36.

Jacobs D. E. : Front-loaded oxfendazole pulse release bolus for the suppression of parasitism in grazing cattle. Vet. Rec., 1987 b, $121,403-404$.

Jacobs et al. : Interactions between chemoprophylaxis and immunity to bovine parasitic gastroenteritis and bronchitis; pilot studies using an oxfendazole pulse release bolus. Res. Vet. Sci., 1987 c, 43, 273-275.

Taylor S. M. et al. : Immunity to parasitic bronchitis of yearling cattle treated with ivermectin during their first grazing season. Vet. Rec., 1988, 123, 391-395. 